\title{
Study on Deformation Behavior of Non-Hardenable Austenitic Stainless Steel (Grade X5CrNi18-10) by Hot Torsion Tests
}

\author{
Imre Kiss* ${ }^{*}$ Vasile Alexa
}

\begin{abstract}
The steel's deformation resistance, in which high strain rates have an important influence on the mechanism of failure, might be obtained from a suitably instrumented torsion test. Determination of stainless steel deformability by hot torsion test is the only method that allows obtaining large deformations along the length of the test specimen, so it is mainly used to determine the characteristics at large plastic deformations. By this method, the hot deformability of stainless steel is determined by subjecting to hot torsion the cylindrical stainless steel specimens maintained at the deformation temperature in a tubular oven belonging to the Laboratory of Metal Rolling and Plastic Deformation, at the Faculty of Engineering - Hunedoara, University Politehnica Timişoara. For the experimental hot torsion tests, several stainless steel grades were used and included in a large series of studies destined to determining the deformation behavior of steel. Having in view the previous results obtained in the study of deformability characteristics of two stainless steels (hardenable martensitic stainless steel, grade $\mathrm{X} 46 \mathrm{Cr} 13$ and non-hardenable ferritic stainless steel, grade $\mathrm{X} 6 \mathrm{Cr} 17$ ), this paper includes the results of the hot torsion tests conducted to find the deformation behavior of the non-hardenable austenitic stainless steel (grade X5CrNi18-10). For analysis of laboratory hot torsion tests results the univariate and multivariate regression analysis was used, estimating the relationships among the hot-testing temperature, torque moment and number of torsions up to the breaking point of the specimens of austenitic stainless steel. Therefore, the optimum range of heating temperatures applied for deforming the studied steels results clearly from the deformability - temperature (plasticity - temperature and deformation resistance - temperature) diagrams. Correlations are useful because they can indicate a predictive relationship that can be exploited in the laboratory or industrial practice.
\end{abstract}

Keywords: austenitic stainless steel; grade X5CrNi18-10; hot torsion test; stainless steel grades; plasticity and deformability

\section{INTRODUCTION}

In many types of industrial operations, the equipment requires steel to withstand high operating temperatures, combined with the corrosive action of the environment [13]. These requirements cannot be met without the proper development of the high-alloy and quality steel manufacture, including the stainless steels, the most diverse and complex family of all steels [1-12].

Austenitic steels are stainless steels that contain high levels of chromium and nickel and low levels of carbon [1,48, 11, 14-16]. Known for their formability and resistance to corrosion, austenitic steels are the most widely used grade of stainless steel. They are formable and weldable, and they can be successfully used at various temperatures - from cryogenic temperatures to the higher temperatures of furnaces [2,8-13]. They contain between about 16 and $25 \%$ chromium, and they can also contain nitrogen in solution, both of which contribute to their high corrosion resistance [12-16].

Were it not for the cost of the nickel that helps stabilize their austenitic structure, these alloys would be used even more widely [1-8]. Particular ranges of sulphur content may provide improvement of particular properties [3-10]. For machinability, a controlled sulphur content of $0.015 \%$ to $0.030 \%$ is recommended and permitted. For weldability, a controlled sulphur content of $0.008 \%$ to $0.030 \%$ is recommended and permitted $[3-5,8-10]$.

Currently, we are familiar with various types of stainless steels, which have multiple features and properties, designed to withstand corrosive environments and various working conditions [1-21]. Austenitic steels, which contain 16-26\% chromium and up to $35 \%$ nickel, usually have the highest corrosion resistance $[1-5,8,12-16]$. They are not hardenable by heat treatment and are non-magnetic. The most common type is the grade, which contains $18 \%$ Chromium and $8 \%$ Nickel.

Stainless heat-resistant steels are always in demand when extreme technical requirements are imposed on the material, due to their outstanding chemical corrosion and mechanical properties $[1-5,14-17]$. The austenitic stainless steel (non-magnetic and non-hardenable stainless steel), grade $\mathrm{X} 5 \mathrm{CrNi} 18-10$, is the standard for the austenitic grades of stainless steel due to its good corrosion resistance, ease of formability and fabrication [14-16,19-21].

Table 1 Chemical composition of steel X5CrNi18-10 [19-21]

\begin{tabular}{|c|c|c|c|}
\hline $\mathrm{C}(\%)$ & $\mathrm{Si}(\%)$ & $\mathrm{Mn}(\%)$ & $\mathrm{Ni}(\%)$ \\
\hline $\max$ & $\max$ & $\max$ & $8-10.5$ \\
0.07 & 1.0 & 2.0 & $\mathrm{~N} \mathrm{( \% )}$ \\
\hline $\mathrm{P}(\%)$ & $\mathrm{S}(\%)$ & $\mathrm{Cr}(\%)$ & $\max$ \\
\hline $\max$ & $\max$ & $17.5-19.5$ & 0.11 \\
0.045 & 0.015 & & \\
\hline
\end{tabular}

Austenitic stainless steels are used in a wide range of applications, including typical applications in automotive parts, food and beverage equipment, storage vessels and pipes for corrosive liquids and industrial equipment (as chemical, pharmaceutical, cryogenic, construction and mining equipment) $[1-10,14-16]$.

\section{RESEARCH AREA}

The key areas of focus in the area of the hightemperature plastic working processes are understanding the critical temperature phases at which recrystallization can be 
prevented and then the start and finish of the austenite transformation [5-10].

For technologists, designers and researchers, the knowledge about the characteristics of deformability (plasticity and deformation resistance) has a great practical significance, because they are important elements in establishing the correct technological process [10-18]. The change of deformation conditions existing in the industrial process, such as the temperature and the rate of deformation, are difficult to consider in correcting the deformability determined by testing. In view of this, deformability is the ability of a material to be plastically deformed without the occurrence of undesired conditions (cracking of the material during the plastic deformation, inadequate quality of the surface, coarse structure, difficulty of material flowing when filling the molds, or other commercially-imposed conditions) [4-10,13-18].

In fact, the deformability of alloys characterizes their ability to permanently deform without breaking the internal links. As the deformability of a material is expressed by the degree of deformation to which the first cracks appear, i.e. its tearing resulting from a standard mechanical test or from one specific to the industrial deformation process, it should be pointed out that the breaking process, for all industrial processes of plastic deformation, as well as for the materials plastically deformed in these processes, appears in the form of ductile fracture [4-10, 13-18].

The behavior of steels during the hot deformation process, such as rolling, is a complex theoretical and practical issue and depends on the process parameters such as deformation size, deformation rate and temperature [1-18]. One of the crucial issues is finding the interdependence between the hot plastic deformation process parameters, the steel's structure and their technological properties.

Determination of stainless steel deformability by hot torsion test is the only one method that allows obtaining large deformations along the length of the test specimen, so it is mainly used to determine the characteristics at large plastic deformations. In order to determine the applicability of a steel type for a particular service, laboratory experiments are sometimes conducted under simulated industrial service conditions and other experiments are designed to determine the specific properties of the material [14-18].

Hot torsion testing is preferred in finding these correlations experimentally, being one of the most widely used methods for the evaluation of the deformation behavior of alloys [14-18]. Traditionally, this method is used to provide basic data for the characterization of the mechanical properties of alloys under shear, but it is also useful for providing the existence of hot ductility as being dependent on both high-temperatures and strain rates of deformation [14-18]. Therefore, the analysis of the high-temperature plastic working process conducted with the application of a hot torsion test, allows the determination of the influence of plastic deformation conditions on the steel's plasticity. In fact, simulating the real industrial hot rolling process, the hot torsion testing can be used to assure the steel's hot rolling process [14-18].
The hot torsion method enables the general determination of deformability characteristics of steels in the laboratory, especially those stainless (plasticity and deformation resistance, depending on temperature) and the study of the influence of deformation conditions (rate of heating, holding time at heating temperature, friction with the tools, rate of deformation, structural changes in terms of deformation, rate of recrystallization, etc.) [12-18].

The indications regarding the variation of plasticity with the temperature, using the hot torsion method, allowed to establishing the temperature range within which the steel plasticity is optimal and in which, in general, it is recommended to perform the entire hot plastic deformation. Also, depending on the plasticity variation with temperature, a more rational distribution of the reduction coefficients per passes can be achieved, so that the plasticity property of the steel can be used as much as possible [14-18].

In the rolling process, during the heating at various speeds, the knowledge of the steel's deformation behavior expressed through two main characteristics - plasticity and deformation resistance - is of particular importance in the structure and quality of rolled products [14-18]. In this sense, we have the following technical remarks:

- Deformation resistance is the resistance that steel opposes in plastic deformability under the conditions of the processes of plastic deformation (i.e. degree and deformation speed, temperature, mechanical scheme of deformation, friction conditions, etc.). In the hot torsion test the magnitude of the torque required to the specimen's torsion expresses the resistance to deformation of that steel.

- Plasticity of steels, also known as plastic deformation, is the property to undergo permanent plastic deformation, a non-reversible change of shape in response to applied rolling forces, without any increase in stresses or loads, being dependent on the deformation speed (i.e. higher stresses usually have to be applied to increase the rate of deformation). In the hot torsion test the plasticity limit is expressed by the number of torsions up to breaking at a given temperature and deformation rate.

The steel's deformation resistance, in which high strain rates have an important influence on the mechanism of failure, might be obtained from a suitably instrumented torsion test [14-18]. In fact, hot torsion testing simulates the thermal and mechanical parameters under very precisely controlled conditions [14-18].

\section{METHODOLOGY FOR HOT TORSION TESTING}

Determination of stainless steel deformability by torsion is the only one that allows obtaining large deformations along the length of the specimen, so it is mainly used to determine the characteristics at large deformations. By this method, the hot deformability of the stainless steel is determined by subjecting to torsion a cylindrical specimen maintained at the deformation temperature in a tubular oven [14-18].

The size of the required moment for torsion when the specimen expresses the resistance to deformation, and the 
number of torsions before failure express the plasticity limit of that steel [14-18]. Since the shear strains play an important role in the process of rolling and forging, the deformability caused by torsion reflects quite accurately the steel behavior at hot plastic deformation. Due to the fact that the specimen can be maintained in the oven during deformation, we can ensure the stability of temperature [14-18].

Existing research infrastructure at the Faculty of Engineering Hunedoara, University Politehnica Timişoara, allows the research to be carried out under the proper conditions, according to the timetable and the duration of performing laboratory experiments on hot testing of several stainless steels [14-18]. The experimental equipment (Figure 1) used to study the stainless steel deformability by hot torsion belongs to the Laboratory of Metal Rolling and Plastic Deformation [14-18].

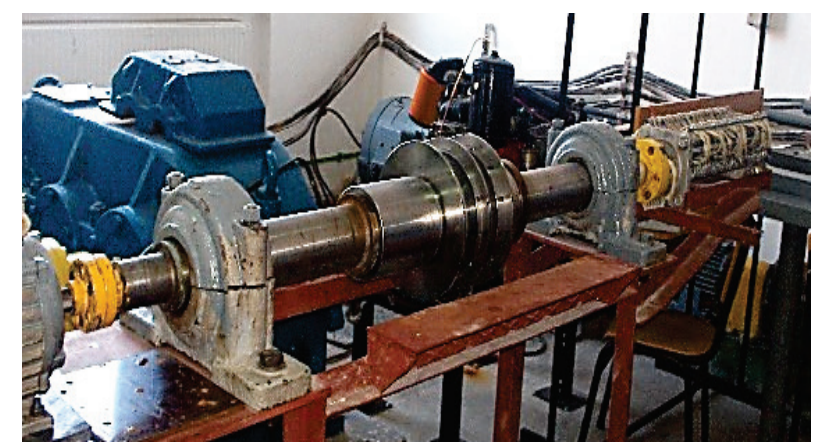

(a)

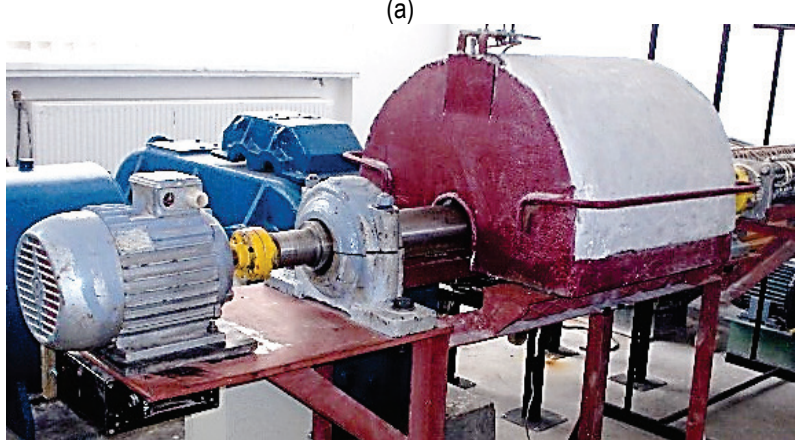

(b)

Figure 1 The equipment for determining the hot deformability of the stainless steels a) without the heating oven; $b$ ) with the heating oven

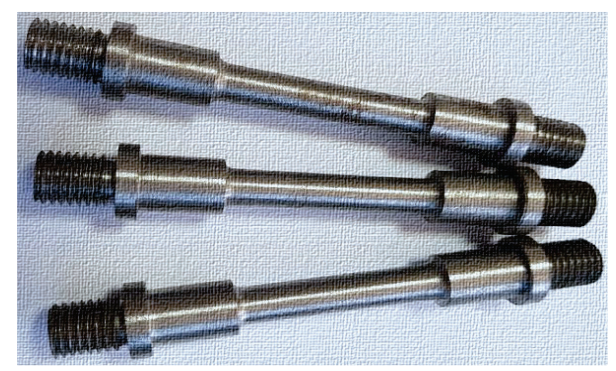

Figure 2 Austenitic stainless steel's sample for determining the hot deformability by torsion

The cylindrical specimens for hot torsion test were mechanically taken from hot-rolled steel bars, having the form and dimensions presented in Fig. 2 [14-18].
The choice of heating regime is currently mostly based on the practical experience of the companies and, therefore, the process of establishing the hot processing technology for these steels is primarily related to the heating conditions, according to their technological characteristics [10-18].

\section{METHODOLOGY FOR MODELLING}

For the analysis of laboratory hot torsion tests results, the univariate and multivariate regression analysis was used [1618]. In statistical modelling, regression analysis is a process for estimating the relationships among various variables, used to understand which among the independent variables are related to the dependent variable [22-24]. More specifically, regression analysis helps one understand how the typical value of the dependent variable (or criterion variable) changes when any one of the independent variables is varied, while the other independent variables are held fixed [22-24]. In our case, we estimated the relationships among the hot-testing temperature, torque moment and number of torsions up to breaking of the specimens of austenitic stainless steel [16-18].

The multivariate regression analysis is a statistical method that is commonly used to develop causal understanding from observational data, i.e. the laboratory hot testing experiments data, in our case. Also, this approach can provide an overall knowledge for evaluating causal hypotheses of the plastic deformation regimes. Correlations are useful because they can indicate a predictive relationship that can be exploited in the laboratory or industrial practice [16-18]. When the coefficient of determination ( $\mathrm{r} 2$ ) value is high (close to 1), it means that the convergence validity is high, indicating that the data have good convergence validity. Statistical graphics can be used to explore multivariate data.

\section{LABORATORY RESULTS AND DISCUSSIONS}

The results of experimental research on deformation behavior of stainless steel conducted by laboratory research have led to the creation of a technological rolling process based on the knowledge of the rolled material, their properties and characteristics.

For the experimental tests, we used several stainless steel grades. This study includes the results of the tests conducted to find the plasticity and deformability characteristics of the austenitic stainless steel, grade X5CrNi18-10 (Tab. 2).

We prepared 40 cylindrical samples (Fig. 2) from the austenitic stainless steel, grade $\mathrm{X} 5 \mathrm{CrNi1}$-10. They were subjected to torsional deformation by maintaining the deformation temperature in the experimental facility of 50 ${ }^{\circ} \mathrm{C}$, within the range $800-1250{ }^{\circ} \mathrm{C}$.

The variation of plasticity (expressed by the number of torsions up to breaking) in correlation with the hot-testing temperature is plotted in the Fig. 3. Also, variation of deformation resistance (expressed by the maximum torque) in correlation with the hot-testing temperature is plotted in Fig. 4. 
Table 2 The results of the tests conducted to find the deformability characteristics of the austenitic stainless steel (non-hardenable stainless steel, grade X5CrNi18-

$10)$, at the experimental heating temperature values $\left(800-1250^{\circ} \mathrm{C}\right)$

\begin{tabular}{|c|c|c|c|c|}
\hline $\begin{array}{l}\text { Hot torsion } \\
\text { experiments } \\
\text { no. }\end{array}$ & 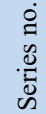 & $\begin{array}{c}\text { Testing } \\
\text { temperature, } \\
\text { (C) }\end{array}$ & $\begin{array}{c}\text { Torque } \\
\text { moment, } \\
(\mathrm{daN} \cdot \mathrm{cm})\end{array}$ & $\begin{array}{l}\text { Number of } \\
\text { torsions up to } \\
\text { breaking, (-) }\end{array}$ \\
\hline \multirow{4}{*}{$\begin{array}{c}\text { AUSTENITIC } \\
\text { STAINLESS } \\
\text { STEEL - I }\end{array}$} & 01 & 800 & 200 & 2 \\
\hline & 02 & 800 & 392 & 2 \\
\hline & 03 & 800 & 340 & 2 \\
\hline & 04 & 800 & 390 & 2 \\
\hline \multirow{4}{*}{$\begin{array}{c}\text { AUSTENITIC } \\
\text { STAINLESS } \\
\text { STEEL - II }\end{array}$} & 05 & 850 & 192 & 3 \\
\hline & 06 & 850 & 362 & 3 \\
\hline & 07 & 850 & 314 & 4 \\
\hline & 08 & 850 & 359 & 2 \\
\hline \multirow{4}{*}{$\begin{array}{c}\text { AUSTENITIC } \\
\text { STAINLESS } \\
\text { STEEL - III }\end{array}$} & 09 & 900 & 276 & 4 \\
\hline & 10 & 900 & 326 & 2 \\
\hline & 11 & 900 & 306 & 3 \\
\hline & 12 & 900 & 316 & 3 \\
\hline \multirow{4}{*}{$\begin{array}{c}\text { AUSTENITIC } \\
\text { STAINLESS } \\
\text { STEEL - IV }\end{array}$} & 13 & 950 & 194 & 6 \\
\hline & 14 & 950 & 230 & 5 \\
\hline & 15 & 950 & 220 & 8 \\
\hline & 16 & 950 & 227 & 4 \\
\hline \multirow{4}{*}{$\begin{array}{c}\text { AUSTENITIC } \\
\text { STAINLESS } \\
\text { STEEL - V }\end{array}$} & 17 & 1000 & 170 & 4 \\
\hline & 18 & 1000 & 176 & 6 \\
\hline & 19 & 1000 & 156 & 7 \\
\hline & 20 & 1000 & 194 & 3 \\
\hline \multirow{4}{*}{$\begin{array}{c}\text { AUSTENITIC } \\
\text { STAINLESS } \\
\text { STEEL - VI }\end{array}$} & 21 & 1050 & 144 & 9 \\
\hline & 22 & 1050 & 130 & 8 \\
\hline & 23 & 1050 & 142 & 8 \\
\hline & 24 & 1050 & 130 & 7 \\
\hline \multirow{4}{*}{$\begin{array}{c}\text { AUSTENITIC } \\
\text { STAINLESS } \\
\text { STEEL - VII }\end{array}$} & 25 & 1100 & 133 & 10 \\
\hline & 26 & 1100 & 123 & 8 \\
\hline & 27 & 1100 & 127 & 15 \\
\hline & 28 & 1100 & 129 & 12 \\
\hline \multirow{4}{*}{$\begin{array}{c}\text { AUSTENITIC } \\
\text { STAINLESS } \\
\text { STEEL - VIII }\end{array}$} & 29 & 1150 & 98 & 9 \\
\hline & 30 & 1150 & 102 & 9 \\
\hline & 31 & 1150 & 100 & 9 \\
\hline & 32 & 1150 & 80 & 9 \\
\hline \multirow{4}{*}{$\begin{array}{c}\text { AUSTENITIC } \\
\text { STAINLESS } \\
\text { STEEL - IX }\end{array}$} & 33 & 1200 & 97 & 9 \\
\hline & 34 & 1200 & 83 & 12 \\
\hline & 35 & 1200 & 84 & 6 \\
\hline & 36 & 1200 & 77 & 6 \\
\hline \multirow{4}{*}{$\begin{array}{c}\text { AUSTENITIC } \\
\text { STAINLESS } \\
\text { STEEL - X }\end{array}$} & 37 & 1250 & 58 & 7 \\
\hline & 38 & 1250 & 44 & 8 \\
\hline & 39 & 1250 & 61 & 6 \\
\hline & 40 & 1250 & 64 & 6 \\
\hline
\end{tabular}

Each point within the temperature range $\left(800-1250^{\circ} \mathrm{C}\right)$ shown in Tab. 2, and their representations in Figs. 2 and 3, represents the arithmetic mean of four independent determinations.

Regarding the graphical representation of the experimental tests results, presented above in Figs. 3-5, the following comments and remarks need to be made:

- the variation of the stainless steel's plasticity (regardless of the analyzed steel grade), as shown in Fig. 2, indicates that it increases with increasing the heating temperature up to $1100-1150^{\circ} \mathrm{C}$; after that it decreases;

- the variation deformation resistance of a stainless steel, as shown in Fig. 3, indicates that the deformation resistance of a stainless steel (regardless of the steel grade) decreases with increasing the heating temperature.

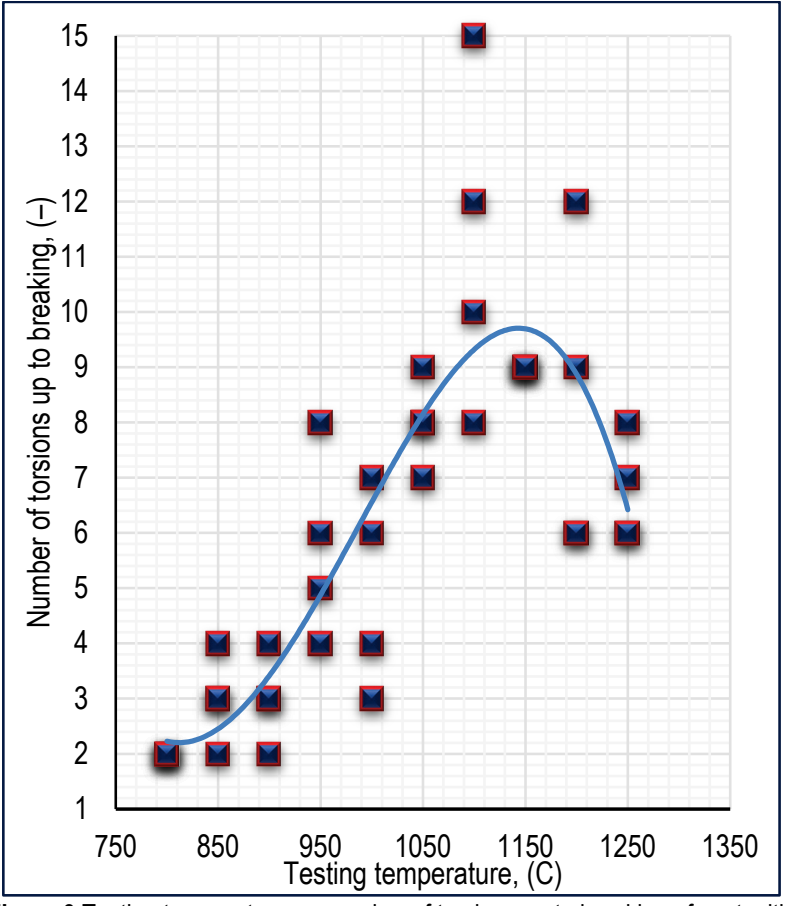

Figure 3 Testing temperature vs. number of torsions up to breaking of austenitic stainless steel (stainless steel, grade X5CrNi18-10), at the experimental heating temperature values $\left(800-1250^{\circ} \mathrm{C}\right)$

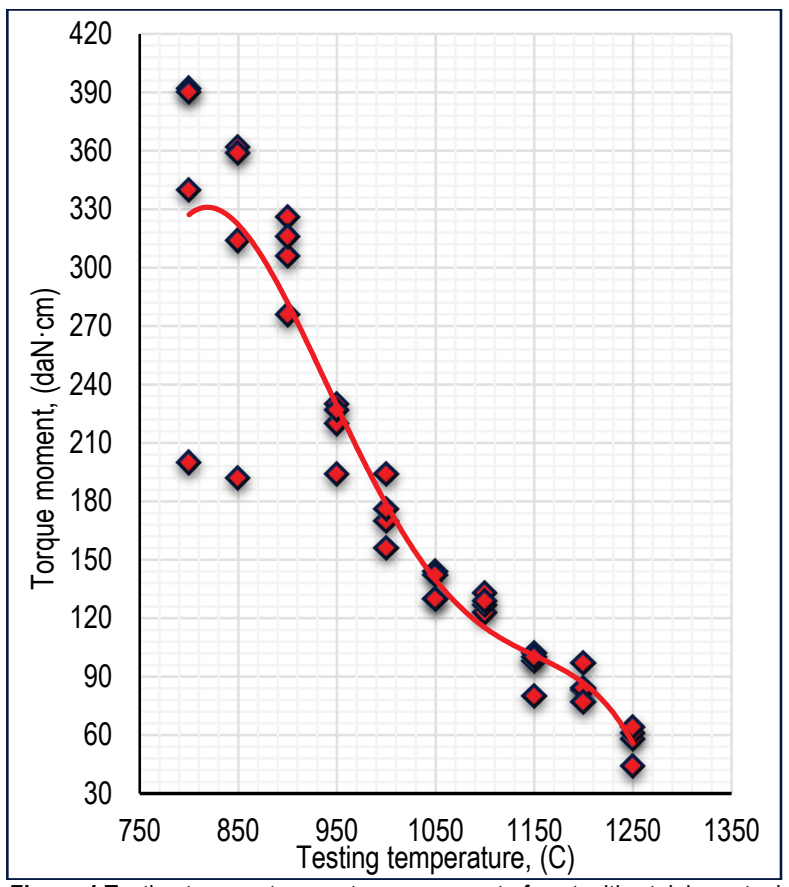

Figure 4 Testing temperature vs. torque moment of austenitic stainless steel (stainless steel, grade $\mathrm{X} 5 \mathrm{CrNi18}-10$ ), at the experimental heating temperature values $\left(800-1250^{\circ} \mathrm{C}\right)$

\section{MODELLING RESULTS AND DISCUSSIONS}

Having in view our laboratory results on the austenitic stainless steel's deformation behavior, and also their analysis, the following remarks need to be made:

- the regression surface of plasticity (number of torsions to failure) of the austenitic stainless steel (grade 
X5CrNi18-10), described by the number of torsions before failure, is shown in Fig. 5;

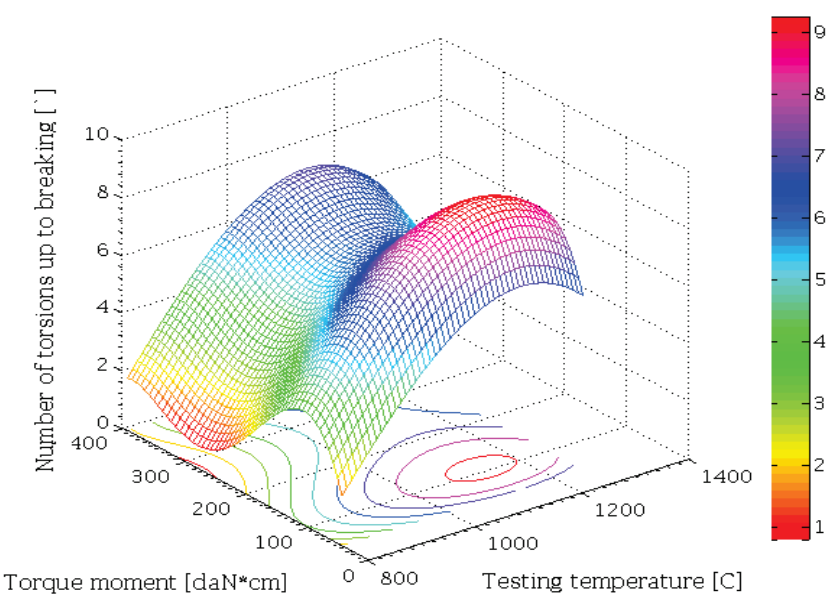

Figure 5 Number of torsions up to breaking vs. torque moment and testing temperature of the austenitic stainless steel (grade X5CrNi18-10), at the experimental heating temperature values $\left(800-1250^{\circ} \mathrm{C}\right)$ [equation type: $z_{1}=a_{1}+$ $a_{2} x+a_{3} x^{2}+a_{4} x^{3}+a_{5} y+a_{6} y^{2}+a_{7} y^{3}+a_{8} y^{4}+a_{9} y^{5}$, coefficient of determination: $r^{2}=$ 0.8340]

- this regression surface can be interpreted by technologists, plotting the regression surface in 2D coordinates (testing temperature vs. torque moment, Fig. 6), and this can be used as deformability diagram for the plasticity of austenitic stainless steel (non-hardenable stainless steel, grade $\mathrm{X} 5 \mathrm{CrNi18}-10$ );

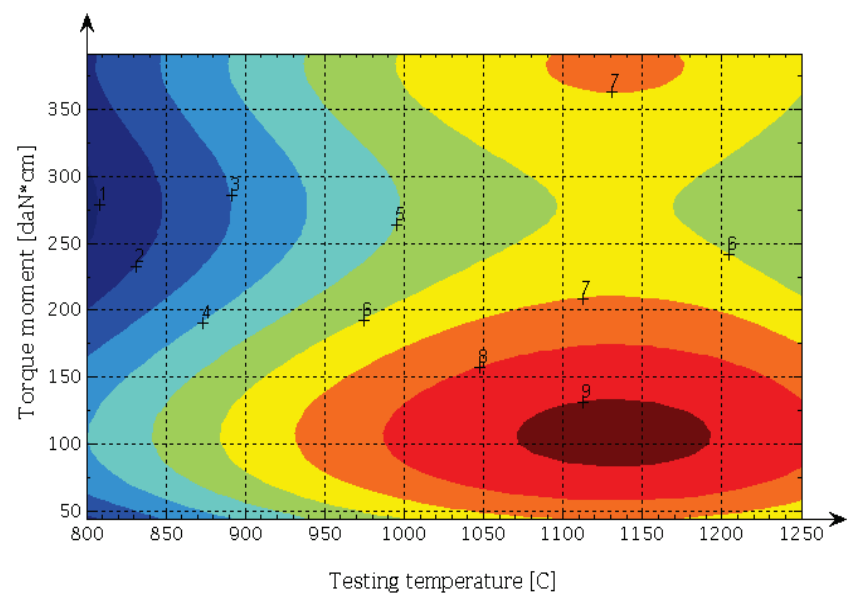

Figure 6 Correlation diagram for technological domains area of resistance to deformation: testing temperature vs. torque moment of the austenitic stainless steel (grade X5CrNi18-10), at the experimental heating temperature values (800-1250

$\left.{ }^{\circ} \mathrm{C}\right)$

- the regression surface of deformation resistance (maximum torque) of the austenitic stainless steel (grade X5CrNi18-10), described by the number of torsions before failure, is shown in Fig. 7;

- this regression surface can be interpreted by technologists, plotting the regression surface in 2D coordinates (testing temperature vs. number of torsions up to breaking, Fig. 8), and this can be used as deformability diagram for deformation resistance of the austenitic stainless steel (non-hardenable stainless steel, grade $\mathrm{X} 5 \mathrm{CrNi18}-10)$;

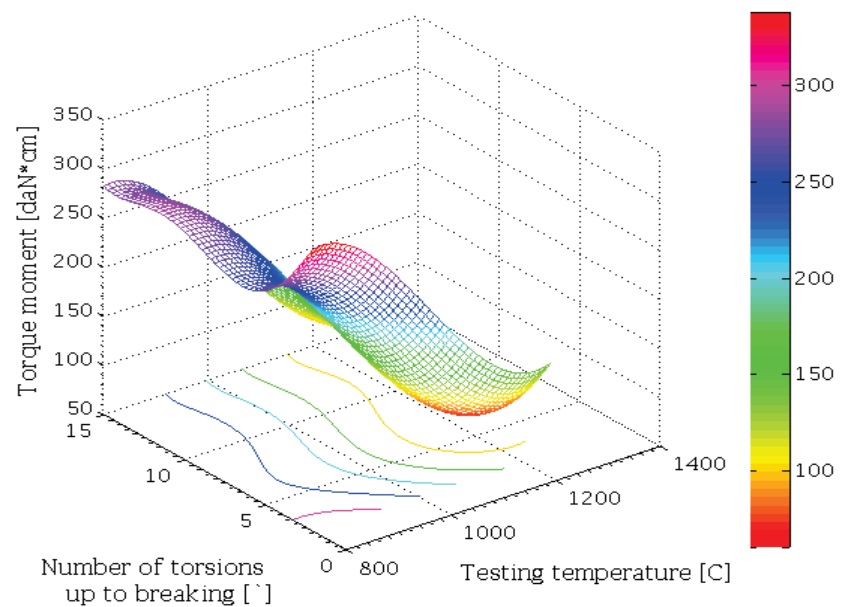

up to breaking [']

Figure 7 Torque moment vs. number of torsions up to breaking and testing temperature of the austenitic stainless steel (grade $\mathrm{X} 5 \mathrm{CrNi18}-10)$, at the experimental heating temperature values $\left(800-1250^{\circ} \mathrm{C}\right)$ [equation type: $z_{2}=a_{1}+$ $a_{2} x+a_{3} x^{2}+a_{4} x^{3}+a_{5} y+a_{6} y^{2}+a_{7} y^{3}+a_{8} y^{4}+a_{9} y^{5}$, coefficient of determination: $r^{2}=$ 0.9389]

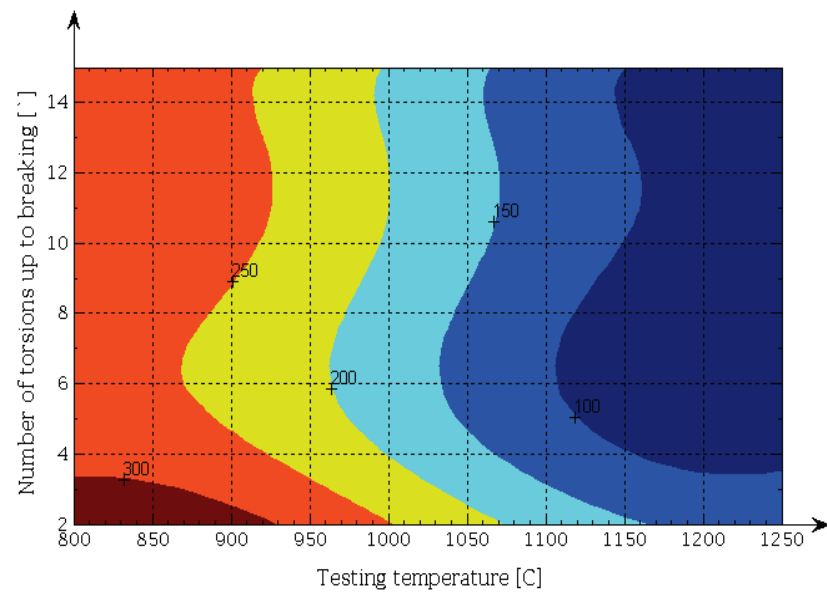

Figure 8 Correlation diagram for technological domains area of plasticity: testing temperature vs. number of torsions up to breaking of the austenitic stainless steel (grade X5CrNi18-10), at the experimental heating temperature values (800-1250 $\left.{ }^{\circ} \mathrm{C}\right)$

Having in view the presented results, the following remarks need to be made:

- the upper limit of heating temperatures applied for deforming the studied steel (austenitic stainless steel, grade $\mathrm{X} 5 \mathrm{CrNi18}-10$ ), as seen in the results from the correlation diagrams (Fig. 5 and Fig. 7), is in the range of $1150-1250^{\circ} \mathrm{C}$;

- the end heating temperature, for the hot deformation of the studied stainless steel grade (austenitic stainless steel), according to the same correlation diagrams (Fig. 5 and Fig. 7), is determined as optimal for $950^{\circ} \mathrm{C}$.

\section{CONCLUSIONS}

The analysis of the laboratory research on deformation behavior of stainless steel conducted domestically and 
abroad shows that the heating process for the stainless steel raises some difficult issues in the rolling process and differs from one rolling company to another, relying mostly on each company's own experience.

On the basis of the principle of shaping processes, which is used as the basic instrument useful in the analysis of the industrial rolling processes, we determined the proper thermal regimes of plastic deformation of austenitic stainless steels, from prism of the laboratory experiment. In fact, hot torsion testing simulates the thermal and mechanical parameters under very precisely controlled conditions.

In this sense, our research proposes and realizes on the one side the analysis of the austenitic stainless steels deformability - analysis materialized from prism of the laboratory experiment by hot torsion testing, and on the other side, the modelling of austenitic stainless steels plastic deformation, using electronic calculus technique in MATLAB area, and, therefore, a mathematical interpretation of the technological processes. The research on austenitic stainless steels deformability using the hot testing method experimentally defines an important chapter in the area of stainless steels plastic deformation. In addition, the mathematical modelling by regression analysis establishes a methodology for the determination of the technological parameters values, for which a rolling temperature has the desirable values or ranges. Since it is disposed of real laboratory data, the regression analysis is based on hot testing data, obtained in our laboratory.

The experimented research on deformability characteristics (plasticity any deformation resistance) of austenitic stainless steel together with the regression analysis of the hot testing results, allow for the conclusion of direct results for the plastic deformation of austenitic stainless steels and their industrial rolling.

In this stage of our research, the high temperature deformability and fracture behavior of the austenitic stainless steel (grade X5CrNi18-10) by experimental hot torsion tests is studied. This method takes into consideration the influence of the heating technology factors to a greater extent; it is simpler for technological calculations and has a better safety coefficient for the industrial practice.

Starting from the range of temperature between 850-900 ${ }^{\circ} \mathrm{C}$, all specimens of austenitic stainless steel have a sufficient plasticity, but the value of the deformation resistance is still high up to the temperature of $1050-1150{ }^{\circ} \mathrm{C}$. The growth dynamic of the plasticity characteristics is continuous, reaching the maximum value at the temperature of $1200{ }^{\circ} \mathrm{C}$, while reducing the resistance to deformation.

Thus, from the hot torsion tests carried out to determine the hot deformability of the austenitic stainless steel (grade $\mathrm{X} 5 \mathrm{CrNi18}-10$ ), it results that the optimal plasticity is found within the temperature range $950-1200^{\circ} \mathrm{C}$.

The temperature may be limited in the real industrial hot rolling process due to the risk of excessive grain growth during heating under industrial conditions (industrial rolling process as the phenomenon that does not occur during the heating at the torsion facility, and thus the values given for plasticity at high temperatures).
Following the analysis of these results, it can be inferred that, in practice, in order to take advantage of maximum plasticity of the austenitic stainless steel, on the one hand, it will have to be deformed at $1150^{\circ} \mathrm{C}$ if the warp speed is high and at $1200{ }^{\circ} \mathrm{C}$ if the speed is low, and on the other hand, high deformation speeds will have to be avoided in cases where work is done with high degrees of reduction.

\section{Acknowledgement}

The laboratory equipment used to study the stainless steel deformability by hot torsion is subject to the patent registered with the State Office for Inventions and Trademarks (OSIM-Romania) under number 439/17.05.2010, entitled "Equipment adapted for experimental determination of the resistance to thermal fatigue of samples placed tangentially on the generator of support discs", No. 54/2011. Additional information about the equipment (description, method, pictures etc.) is available in the studies [16-18], according to the below-presented references list.

\section{REFERENCES}

[1] Sourmail, T. \& Bhadeshia, H. K. (2005). Stainless steels, http://thomas-sourmail.net/stainless/ https://doi.org/10.1016/B978-075068084-4/50014-5

[2] Sivaprasad, P. V., Girase, N., Sarkar, S., \& Wijk, O. (2013). Role of modelling in the development of high performance steels for important engineering applications. Advanced Materials Research, 794, 493-501. https://doi.org/10.4028/www.scientific.net/AMR.794.493

[3] Lo, K. H., Shek, C. H., \& Lai, J. K. (2009). Recent developments in stainless steels. Materials Science and Engineering: R: Reports, 65(4-6) 39-104. https://doi.org/10.1016/j.mser.2009.03.001

[4] Byun, T. S., Hashimoto, N., \& Farrell, K. (2004). Temperature dependence of strain hardening and plastic instability behaviors in austenitic stainless steels. Acta Materialia, 52(13) 38893899. https://doi.org/10.1016/j.actamat.2004.05.003

[5] Kuc, D. \& Niewielski, G. (2009). Technological plasticity and structure in stainless steels during hot-working. Journal of Achievements in Materials and Manufacturing Engineering, 32(2), 154-161.

[6] Yanushkevich, Z., Belyakov, A., \& Kaibyshev, R. (2015). Microstructural evolution of a 304-type austenitic stainless steel during rolling at temperatures of 773-1273K. Acta Materialia, 82 244-254. https://doi.org/10.1016/j.actamat.2014.09.023

[7] Sun, H., Sun, Y., Zhang, R., Wang, M., Tang, R., \& Zhou, Z. (2015). Study on hot workability and optimization of process parameters of a modified 310 austenitic stainless steel using processing maps. Materials \& Design, 67 165-172. https://doi.org/10.1016/j.matdes.2014.11.041

[8] Surovtsev, A. P. \& Sukhanov, V. E. (1990). Features of the deformability of corrosion-resistant chromium-nickel steels of the austenitic class. Metal science and heat treatment 32(6), 431-436. https://doi.org/10.1007/BF01100162

[9] Gozzi, J. (2004). Plastic behaviour of steel: Experimental investigation and modelling (Doctoral dissertation, Luleå tekniska universitet). 
[10] Ilca, I. (2016). The theory and practice of heating quality steel ingots, Journal of Engineering Science Innovation, 1 120-130

[11] Ilca, I. (2017), Optimization of hot-metal working of austenitic stainless steels. Journal of Engineering Sciences and Innovation 2(3) 103-117.

[12] Ilca, I., Kiss, I., Alexa, V., \& Rațiu, S. (2016) Analysis of some steel behaviour at high operating temperatures. Annals of the Faculty of Engineering Hunedoara - International Journal of Engineering 14(2) 183-189.

[13] Ilca, I. (2019). Structural research at high temperature on industrial semi-finished products made from thermostable stainless steels. IOP Conference Series: Materials Science and Engineering, IOP Publishing, 477(1) 012001. https://doi.org/10.1088/1757-899X/477/1/012001

[14] Magaone, J., Ilca, I., \& Alexa, V. (2012). Hot deformability of austenitic stainless steel. Ştiinţa şi Inginerie, 22, AGIR Press, Bucureşti, 241-248.

[15] Magaone, J. \& Ilca, I. (2009). Influence factors analysis and steels behavior within the high temperature operating. Ştiinţa şi Inginerie, 16, AGIR Press, Bucureşti, 629-636.

[16] Alexa, V. \& Kiss, I. (2018). Experimental tests on the plasticity and deformability characteristics of several stainless steel grades used for hydro-pneumatic equipment's manufacturing. Acta Polytechnica Hungarica 15(8) 121-139.

[17] Alexa, V. \& Kiss, I. (2019). Deformability of martensitic stainless steel (grade X46Cr13) by hot torsion. Annals of Faculty Engineering Hunedoara - International Journal of Engineering, 17(2), 209-214.

[18] Kiss, I. \& Alexa, V. (2020). Study on the deformability characteristics of steels for seamless tubes and pipes destined for the petrochemical industry. Acta Polytechnica Hungarica, 17(5), 89-111. https://doi.org/10.12700/APH.17.5.2020.5.5

[19] EN 10088-2: 2005 - Stainless steels - Technical delivery conditions for sheet/plate and strip of corrosion resisting steels for general purposes.

[20] EN 10088-3: 2005 - Stainless steels - Technical delivery conditions for semi-finished products, bars, rods, wire, sections and bright products of corrosion resisting steels for general purposes.

[21] EN 10272: 2007 - Stainless steel bars for pressure purposes

[22] Draper, N. R. \& Smith, H. (1998). Applied regression analysis, 326, John Wiley \& Sons. https://doi.org/10.1002/9781118625590

[23] Jolliffe, I. T. (1986). Principal components in regression analysis. In Principal component analysis, Springer, New York, 129-155. https://doi.org/10.1007/978-1-4757-1904-8_8

[24] Seber, G. A. \& Lee, A. J. (2012). Linear regression analysis, 329, John Wiley \& Sons.

\section{Authors' contacts:}

Imre Kiss, $\mathrm{PhD}$, Associate Professor

(Corresponding author)

University Politehnica Timisoara,

Faculty of Engineering Hunedoara,

Department of Engineering and Management,

5, Revolutiei, 331128 Hunedoara, Romania

tel.: +40254 207588; e-mail: imre.kiss@fih.upt.ro

Vasile Alexa, PhD, Associate Professor

University Politehnica Timisoara,

Faculty of Engineering Hunedoara,

Department of Engineering and Management,

5, Revolutiei, 331128 Hunedoara, Romania

tel.: +40254 207588; e-mail: vasile.alexa@fih.upt.ro 